\title{
Estimation of Rubber Price Returns Using Quantile Regression
}

\author{
Kwadwo Agyei Nyantakyi*, B.L. Pieris, L.H.P. Gunaratne \\ Postgraduate Institute of Agriculture \\ University of Peradeniya \\ Sri Lanka
}

\begin{abstract}
The rubber industry in Sri Lanka is of much economic importance. The current world consumption of rubber, totalling around 18 million tonnes per year, consists of $48 \%$ natural rubber (NR). Thus, in terms of quantity by type, NR is still the largest. Price returns on rubber have effect on both its production and replanting and also the GDP of the Sri Lankan economy in the long run and the world economy. Therefore, accurate analysis and prediction of the price returns on the asset become very important since the supply of agricultural products in the future is affected by continuous future price uncertainties or volatility. Quantile regression was used for the estimation, prediction and analysis of the effects of price returns on rubber production and GDP of Sri Lanka. There were high changes at the percentile $75 \%, 90 \%$, and the $95 \%$ which shows that the rate of change of price decreased drastically with a unit increase in production. At the $50 \%$ percentile, the values coincide with that of the conditional mean value with all other quantile having varying rate of change of price with respect to a unit change in production. For each quantile, a regression model was fitted.
\end{abstract}

Keywords: Asset returns, production, price, quantiles, rubber

\section{INTRODUCTION}

Rubber industry is of much economic importance. Natural rubber is unique in the sense that it is consumed as an industrial raw material but produced as an agricultural commodity. Currently, $80 \%$ of rubber is produced by smallholders. Consequently, it becomes a social commodity where more than 30 million small farmers are at stake worldwide. It has been used for producing various products such as tyres, cooking utensils, medicine, chairs to name a few. It has a life span of 30 years, hence the need to study how it can be sustained.

Sri Lanka is one of the nine major producers of natural rubber, and in terms of productivity, it is now the third best following India and Indonesia. Rubber is grown in as many as 15 districts in Sri Lanka. The areas under cultivation in Sri Lanka were 5200, 1000, 3600 ha in 2007, 2008 and 2009, respectively. In 2009, exports of natural rubber were worth Rs 11.3 billion and those of manufactured rubber products, Rs 44.3 billion. The total exports were worth Rs 56 billion. In 2010, the total had gone up to Rs64 billion. Replanting of rubber seem to be decreasing which may partly be due to lower increases in rubber prices which seem to act as a discouraging factor on replanting. Many studies have been conducted in this area using different methods.

We believe that the use of the conditional mean does not explain well the variations in the data and the quantile regression model parameters may vary within the 
quantiles $[0,1]($ Koenker, 2005).We therefore, in this paper propose the use of quantile regression for the estimation, prediction and analysis of the effects of price returns on rubber production and the GDP of Sri Lanka.

\section{Objective}

Objective of this study are 1) to study the effects of price returns of rubber and its influence on production, replanting decision and the GDP of Sri Lanka, 2) to investigate effects of prices of rubber on replanting decision of rubber growers, 3) to investigate the pattern of the effect of price on production and 4). to investigate if these volatility changes can be captured by the quantile regression.

\section{MATERIALS AND METHODS}

\section{Data Source}

Secondary annual data was collected from FAOSTAT, food balance sheet, price statistics, Department of Census and Statistic Sri Lanka (FAOSTAT, DCS - 2012). These data comprises of the production, imports, exports and prices of rubber, and the data ranges from $1966-2010$.

\section{Statistical Software}

The R software, with the package 'Quantreg' was used in fitting the conditional quantile regression models.

\section{Methodology}

Given $Y_{\mathrm{i}}=f\left(X_{\mathrm{i}}\right)+U_{\mathrm{i}}$ then the $\tau^{\text {th }}$ quantile equation is given by $Y_{i}=\alpha(\tau)+\beta_{i}(\tau) X_{i}+U_{i}$ where $\mathrm{\tau e}[0,1]$

Where $Y_{i}$ is production at time $i\left(000^{*} \frac{h a}{y e a r}\right), X_{i}$ is the average price of rubber deflated by GDP-deflator.

An equation is fit for each quantile.Given a real valued random variable $\mathbf{Y}$ with a distribution function $\mathbf{F}_{\mathbf{V}}(\mathbf{y})=\mathbf{P}(\mathbf{Y} \boldsymbol{\xi} \mathbf{y})$ by Koenker (1982) and L Zhao, et al. (2008) the $\tau^{\text {th }}$ quantile of $\mathbf{Y}$ is given by

$Q_{Y}(\tau)=F_{Y}^{-1}(x)=\inf \left\{y=F_{Y}(y) \geq \tau\right\}$ where $\tau e[0,1]$. Thus the conditional quantile $Q(\tau \mid X)$ are the inverse of the conditional distribution function of the response variables.

Defining the loss function as $\rho_{\mathrm{t}}(\mathrm{y})=\mathrm{y}(\mathrm{\tau}-\mathrm{I}(\mathrm{y}<0))$.

A specific quantile can be found by minimizing the expected loss of $\mathbf{Y}-\mathbf{u}$ with respect to u:

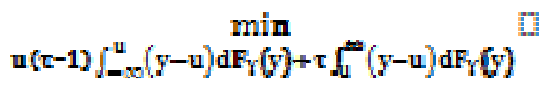

By setting the derivative of the loss function to zero (0) and letting $\mathbf{q}_{\mathbf{r}}$ to be the solution of 
This equation then reduces to:

$$
0=(1-\tau) \int_{-\infty}^{q_{\tau}} d F_{Y}(y)-\tau \int_{q_{\tau}}^{\infty} d F_{Y}(y)
$$

$$
0=\mathrm{F}_{\mathrm{V}}\left(\mathbf{q}_{\mathrm{\tau}}\right)-\mathrm{\tau}
$$

Therefore: $\mathbb{F}_{\mathbf{V}}\left(q_{\tau}\right)=\tau$. Hence $\boldsymbol{q}_{\boldsymbol{\tau}}$ is the $\tau^{\text {th }}$ quantile of the random variable $\mathbf{Y}$.

Suppose the $\tau^{\text {th }}$ conditional quantile function is

$$
Q_{\bar{y}}(\mathrm{x})=\mathrm{X} \beta_{\mathrm{\tau}}
$$

Given the distribution function of $\mathbf{Y}, \boldsymbol{\beta}_{\mathbf{E}}$ can be obtained by solving

$$
\beta_{\mathrm{T}} \arg \overline{\mathrm{II}}=\min _{\beta \in \mathrm{R}^{\mathrm{k}}} \mathrm{E}\left(\boldsymbol{\rho}_{\mathrm{\tau}}(\mathrm{V}-\mathrm{X} \beta)\right) \text {. }
$$

Solving the sample analog gives the estimate of $\beta$.

$$
\overrightarrow{\beta_{\mathrm{r}}} \arg =\min _{\beta \in \mathbb{R}^{k}} \sum_{\mathrm{i}=1}^{\mathbf{n}}\left(\rho_{\mathrm{\tau}}\left(\mathbf{Y}_{\mathrm{i}}-\mathbf{x} \beta\right)\right)
$$

Therefore, using LS estimators for $\alpha(z)$ and $\beta_{1}(z)_{\text {We have }}$

$$
Y_{i}=\alpha(\tau)+\beta_{1}(\tau) X_{i}+U_{i}
$$

where

$$
\left.s\left(\hat{\beta_{1}}(\tau)\right)=\sum_{y \rightarrow R_{i} \beta_{1}}^{n}(\tau) \gamma_{i}-\beta_{1}(\tau) X_{i}\right)+\sum_{y=N_{i} \beta_{1}}^{n}(1-\tau)\left(Y_{i}-\beta_{1}(\tau) X_{i}\right)
$$

$$
\frac{\partial \mathrm{Q}_{\mathrm{Y}}(\tau)}{\partial x_{i}}=\beta_{\mathrm{\tau}}
$$

\section{RESULTS AND DISCUSSION}

It is inappropriate to use the conditional mean to describe the relationship since the data shows a varying rate of change at different quantiles( $Q u, 2008)$. Hence, the need to use quantile for the analysis and prediction of the relation between production and price.

The summary statistic of production and price from the quantile regression is given in Table 1.

Table 1. Statistical summary of production and price

\begin{tabular}{llllll}
\hline Variable & Obs. & Mean & Std. Dev. & Min & max \\
\hline Price & 45 & 50326.27 & 7166.79 & 1740 & 313130 \\
Production & 45 & 123448.4 & 21539.46 & 86230 & 159158 \\
\hline
\end{tabular}

From Table 1, it can be observed that the average price of rubber between 1966-2010 was Rs 50320.27 (\$390) per year with a minimum price of Rs 1740 (\$13.5) and maximum of Rs313130 (\$2427.4) per year. Quantile regression parameter estimates, standard errors and confidence intervals for production and price of rubber are given in Table 2. 
Table 2. Quantile regression parameter estimates, standard errors and confidence intervals for production and price of rubber.

\begin{tabular}{|c|c|c|c|c|c|c|}
\hline Quantiles & Price & Coef. & Std. err & $\mathrm{t}$ & $\mathrm{p}>|\mathrm{t}|$ & $95 \%$ C.I \\
\hline \multirow[t]{2}{*}{0.10} & Production & -.77750 & .042758 & -18.18 & 0.00 & $-.863737-.691277$ \\
\hline & Constant & 107547.3 & 4722.55 & 22.77 & 0.00 & $98023.0 \quad 117071.2$ \\
\hline \multirow[t]{2}{*}{0.25} & Production & -.7896214 & .090011 & -8.77 & 0.00 & $-.971147-.608095$ \\
\hline & Constant & 114879.1 & 11412.9 & 10.07 & 0.00 & $91862.5 \quad 137895.5$ \\
\hline \multirow[t]{2}{*}{0.50} & Production & -.81017 & .145996 & -5.55 & 0.00 & $-1.10460-.515739$ \\
\hline & Constant & 127371.4 & 18253.5 & 6.98 & 0.00 & $90559.7 \quad 164183$ \\
\hline \multirow[t]{2}{*}{0.75} & Production & -1.376476 & 1.5425 & -0.89 & 0.05 & $-4.48720 \quad 1.73425$ \\
\hline & Constant & 219343.4 & 194639 & 1.13 & 0.03 & $-173184 \quad 611871$ \\
\hline \multirow[t]{2}{*}{0.90} & Production & -3.83302 & 1.03758 & -3.69 & 0.00 & $-5.92551-1.74052$ \\
\hline & Constant & 612055.8 & 136493 & 4.48 & 0.00 & $\begin{array}{ll}-5.9255 & -1.74052\end{array}$ \\
\hline \multirow[t]{2}{*}{0.95} & Production & -4.25782 & .389735 & -10.92 & 0.00 & $\begin{array}{ll}-5.04379 & -3.47184\end{array}$ \\
\hline & Constant & 757433.5 & 39946.9 & 18.96 & 0.00 & $676873 \quad 837994$ \\
\hline
\end{tabular}

From the results in Table 2, looking at the varying values of the quantile [0,1] it could be observed that using the conditional mean to describe the data would not be appropriate, hence the appropriateness of the use of the quantile regression for the analysis. From the quantiles at percentile $10 \%$ (i.e. $\geq 90 \%$ ) we see price change with respect to production is about $77.7 \%$ that is there is about $77.7 \%$ decrease in price as a result of increase in production. There is again an increase in the rate of change at the percentile $25 \%$ (i.e., $75 \%$ ) which is about $78.9 \%$ decrease in price for a unit increase in production. There is a further high rate of change to the $81 \%$ decrease in price with a unit increase in production at the percentile $75 \%$. There is then a very high decrease in the rate of change of price with respect to a unit increase in production to about $137 \%$, which increased further to about $383 \%$ change at the percentile (90\%) and goes further to $424 \%$ at the percentile $(95 \%)$.

It could be realised that if the $50 \%$ percentile rate of change of price with respect to production were to be used it would not have given the true nature of the data. Below is Fig. 1 showing the plot of the magnitude of parameter estimates across the various quantiles. 
(Intercept)

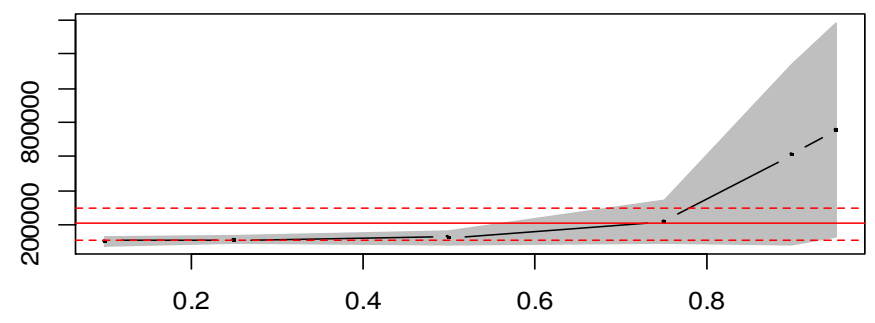

Production

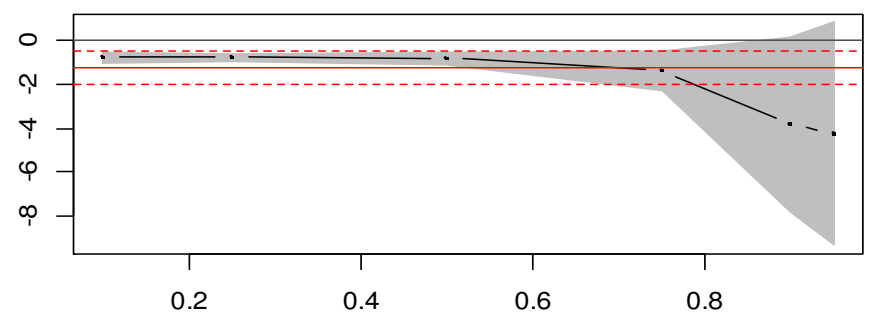

Fig. 1. Plot of the quantiles of the dependent variable on the horizontal axis, the magnitude of the coefficients on the vertical axis.

From Fig. 1, the OLS coefficient is plotted as a horizontal red line with the confidence interval as two red dashed horizontal lines around it. The OLS coefficient does not vary across the quantiles.

The quantile regression coefficients are plotted as the black lines varying across the quantile with confidence interval around it in light blue colour. The quantile intercept lie below the OLS intercept at low quantiles and higher above it at high quantiles.

The coefficients of the production estimates at low quantiles lie above the OLS estimates and decrease below the OLS at higher quantiles. This shows that at higher quantiles, increasing production decreases the price which is significantly different from the OLS estimated line as shown on Fig. 1 production.

Hence, using the quantile analysis we could describe various parts of interest of the production data appropriately instead of depending only on the conditional mean. The quantile plot of production is given in Fig. 2. 


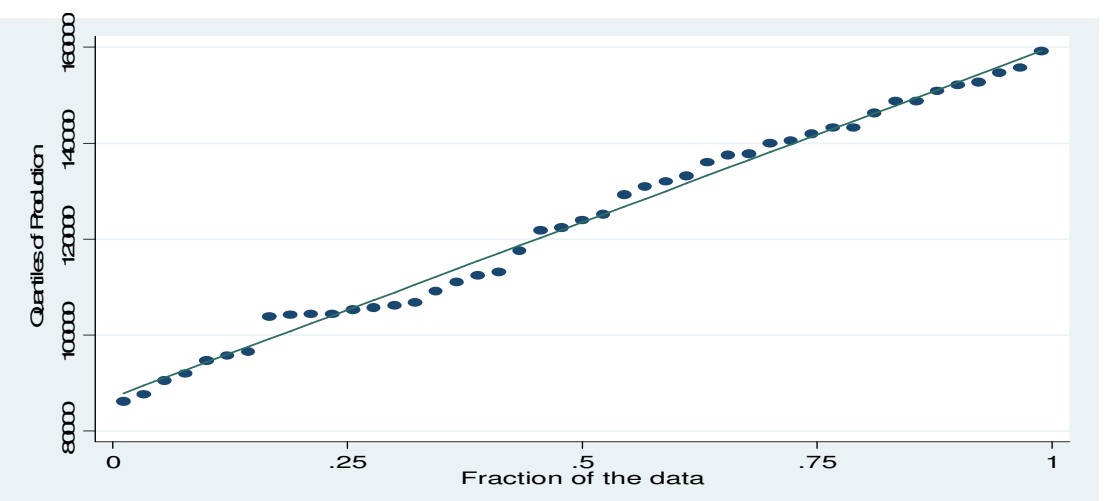

\section{Fig. 2. Quantile plot of production}

From Fig. 2 it could be observed that the quantile plot of production fits almost perfectly well. Hence, the linear quantileis well fit to the data.

\section{CONCLUSIONS}

From the forgone analysis, it can be observed that the quantile regression analysis gives a better insight to the model analysis than the conditional mean. There were very high changes at the percentile $75 \%, 90 \%$, and the $95 \%$ which shows that the rate of change of price decreased drastically with a unit increase in production. Since the percentile $10 \%$ gives the lowest decrease in price with a unit increase in production, its quantile regression model is the best for the prediction. Hence, we are able to look at the effect of price on production at the various quantiles of the regression.

\section{REFERENCE}

Bassett, G. and R. Koenker. (1982). "Tests of linear hypotheses and L1 estimation", Econometrica, 50, 1577 - 83.

Chaudhuri, P., (1991). Nonparametric estimates of regression quantiles and their local Bahadur representation. Annals of Statistics 19, 760 - 777.

Chen, K.Z. Ying, Zhang, H and Zhao, L. (2008). Analysis of least absolute deviations, Biometrika, 95, 107 - 122.

FAOSTAT, Sri Lanka Annual Data (1966-2010), [on line].[Accessed on 10.02.2014]. Available at http://faostat.fao.org.

Gutenbrunner, C., Jureckova, J., Koenker, R, and S. Portnoy (1993). Tests of linear hypotheses based on regression rank scores, J. of Nonparametric Statistics, 2, 307 - 331.

Koenker, R.W. and Bassett, G.W. (1982). Robust tests for heteroscedasticity based on regression quantiles, Econometrica, 50, 43 - 61. 
Koenker, R.W. (2005). Quantile Regression, Cambridge U. Press.

Marc Nerlov and Peter Jr., R.K. (1984), "The Supply Response of Rubber in Sri Lanka", World Bank Staff Working Paper, 657.

Nyblom, J., (1989). "Testing for the constancy of parameters over time". Journal of the American Statistical Association 84, 223 - 230.

Annual Report. (2010). Sri Lanka Tea Board. 574, Galle Road. Colombo 03. Sri Lanka. Issn: $1391-1414$.

Qu, Z., 2008. Testing for structural change in regression Quantiles. Journal of Econometrics $146,170-184$. 